\title{
Exploiting Genetic Diversity for Adaptation and Mitigation of Climate Change: A Case of Finger Millet in East Africa
}

\author{
EO Manyasa ${ }^{1,2}$, P Tongoona ${ }^{2}$, P Shanahan ${ }^{2}$, S Githiri ${ }^{2}$, H Ojulong ${ }^{1}$ and A Rathore ${ }^{3}$ \\ ${ }^{1}$ International Crops Research Institute for the Semi-Arid Tropics (ICRISAT), PO Box 39063, Nairobi 00623, Kenya. \\ ${ }^{2}$ School of Agricultural, Earth and Environmental Sciences, University of KwaZulu-Natal, Private Bag X01, Scottsville, \\ Pietermaritzburg 3209, South Africa. \\ ${ }^{3}$ ICRISAT, Patancheru-502 324, Telangana, India.
}

\begin{abstract}
Eighty one finger millet germplasm accessions from East Africa were evaluated in eight environments in Kenya, Tanzania and Uganda for adaptation and grain yield stability, genotype and genotype $\mathrm{x}$ environment (GGE) models. Lanet 2012 long rains, Serere 2012 long rains and Miwaleni 2012 long rains were found to be the most discriminating environments for the low temperature, sub-humid mid-altitude and dry lowland areas, respectively. Seven genotypes were identified for yield stability across the eight environments, whereas nine genotypes had specific adaptation. Fourteen genotypes attained the highest grain yield and had varied maturity, plant heights and grain colour. This will provide farmers the opportunity to select genotypes appropriate to their target agroecologies with desired traits. The East African finger millet germplasm has high potential as a source of climate smart, high yielding genotypes for direct production and/or breeding.
\end{abstract}

\section{Key Words: Finger Millet, Genetic Diversity, GGE, Yield Stability}

\section{Introduction}

Finger millet in East Africa is mainly grown in the sub-humid to humid zones of Lakes Victoria and Tanganyika, where blast disease (caused by the fungus Magnaporthe grisea) thrives, the cool highlands with low temperatures and to a lesser extent in the low rainfall lowlands that suffer from moisture stress/drought. Finger millet has been reported to be sensitive to temperature extremes. Very high temperatures $\left(38^{\circ} / 28^{\circ} \mathrm{C}\right.$ compared to $32^{\circ} / 22^{\circ} \mathrm{C}$ ), decrease panicle emergence, number of seeds per panicle, grain yield and harvest index (Opole, 2012) whereas low temperatures have been reported to affect pollination and fertilization processes (Bandyopadhyay, 2009). The improved cultivars available in the region have been derived mainly from germplasm selections (Oduori, 2008). The extent of significant genotype by environment $(G \times E)$ interactions determine the consistency of performance of genotypes across locations and seasons. Partitioning of $\mathrm{G} \times$ E interaction into Genotype $\times$ Locations and Genotype $\times$ Years within Locations enables the identification of genotypes with specific adaptation to an environment or with wide adaptability (Yan and Tinker, 2006; Das et al., 2011). In East Africa, no G×E studies have been reported in finger millet and most cultivar selections have been based on individual location testing. This limits the appreciation of the performance potential of many cultivars in other agro-ecologies not used as test sites. Significant $G \times E$ interactions for grain yield and yield components in finger millet have been reported in India by, among others, Misra et al. (2010) and Joshi et al. (2005) and in Ethiopia by Bezaweletaw et al. (2006). This study was conducted to evaluate the $\mathrm{G} \times \mathrm{E}$ interaction and yield stability of 81 finger millet accessions selected from an East African germplasm pool.

\section{Materials and Methods}

\section{Experimental Material}

A total of 81 genotypes (which included five checks-U 15, KNE 814, KNE 479, Nakuru FM 1 and Kahulunge) with high productivity potential were used in this study (Table 1). These comprised selection from 420 accessions ( 340 landraces and 80 minicore set) previously phenotyped across four locations in Kenya.

\section{Test Environments and Experimental Design}

Trials were tested in eight environments (Table 2). They were planted in a $9 \times 9$ square lattice design with two replications per environment; each experimental plot comprising three $4 \mathrm{~m}$ length rows with inter-row and intra-row spacing of $0.4 \mathrm{~m}$ and $0.1 \mathrm{~m}$, respectively. Seeds were manually drilled in furrows and thinned two weeks after emergence to 41 plants per row. Fertilizer application, weeding and pest control were done according to recommended practices. Data collected for

\footnotetext{
*Author for Correspondence: E-mail: e.manyasa@cgiar.org
}

Indian J. Plant Genet. Resour. 30(2): 115-119 (2017) 
Table 1. The finger millet genotypes (81) used for $\mathrm{G} \times \mathrm{E}$ evaluation

\begin{tabular}{|c|c|c|c|c|c|c|c|c|}
\hline Genotype & Name & Origin & Genotype & Name & Origin & Genotype & Name & Origin \\
\hline G1 & Emiroit/Engeny & Uganda & G28 & Gulu E & Uganda & G55 & GBK-040468A & Kenya \\
\hline G2 & Ekama-white & Uganda & G29 & GBK-011110A & Kenya & G56 & GBK-043163A & Kenya \\
\hline G3 & Kal & Uganda & G30 & GBK-011141A & Kenya & G57 & Acc \# 79 & Minicore \\
\hline G4 & Kal & Uganda & G31 & GBK-027145A & Kenya & G58 & Acc \# 3924 & Minicore \\
\hline G5 & Kal Atari & Uganda & G32 & GBK-027201A & Kenya & G59 & Р 224 & Uganda \\
\hline G6 & Kal Atari & Uganda & G33 & IE 4497 & Minicore & G60 & Unknown & Uganda \\
\hline G7 & Kal atari & Uganda & G34 & Ekama & Tanzania & G61 & Etiyo -brown & Uganda \\
\hline G8 & Ekamo & Uganda & G35 & IE 5306 & Minicore & G62 & Ekama & Uganda \\
\hline G9 & Unknown & Uganda & G36 & IE 6154 & Minicore & G63 & Kal & Uganda \\
\hline G10 & RW 127 (IE 6613) & Uganda & G37 & KNE 1034 & Kenya & G64 & Otara chigal & Uganda \\
\hline G11 & GBK-008301 A & Kenya & G38 & Acc \# 3989 & Minicore & G65 & GBK-000352A & Kenya \\
\hline G12 & GBK-011116A & Kenya & G39 & Eteke & Uganda & G66 & GBK-011113A & Kenya \\
\hline G13 & GBK-011136A & Kenya & G40 & Adalaka & Uganda & G67 & GBK-011119A & Kenya \\
\hline G14 & GBK-029681A & Kenya & G41 & Kal & Uganda & G68 & GBK-027200A & Kenya \\
\hline G15 & Acc \# 2954 & Minicore & G42 & GBK-000347A & Kenya & G69 & GBK-029646A & Kenya \\
\hline G16 & Acc \# 3656 & Minicore & G43 & GBK-000351A & Kenya & G70 & GBK-029672A & Kenya \\
\hline G17 & Aсc \# 3779 & Minicore & G44 & GBK-000368A & Kenya & G71 & GBK-029768A & Kenya \\
\hline G18 & Kafumbata & Tanzania & G45 & GBK-000373A & Kenya & G72 & GBK-043166A & Kenya \\
\hline G19 & Kaulunge & Tanzania & G46 & GBK-000410A & Kenya & G73 & IE 2430 & Minicore \\
\hline G20 & 3953 & Tanzania & G47 & GBK-011111A & Kenya & G74 & IE 4121 & Minicore \\
\hline G21 & Purple & Uganda & G48 & GBK-011129A & Kenya & G75 & Ngome & Uganda \\
\hline G22 & Engenyi & Uganda & G49 & GBK-011133A & Kenya & G76 & Katila & Uganda \\
\hline G23 & Unknown & .Uganda & G50 & GBK-011137A & Kenya & G77 & KNE 479 & Kenya \\
\hline G24 & Acomomcomo & Uganda & G51 & GBK-027149A & Kenya & G78 & KNE 814 & Kenya \\
\hline G25 & Lowa & Uganda & G52 & GBK-027155A & Kenya & G79 & Nakuru FM 1 & Kenya \\
\hline G26 & Omunga & Uganda & G53 & GBK-028590A & Kenya & G80 & U 15 & Uganda \\
\hline G27 & Kal & Uganda & G54 & GBK-040463A & Kenya & G81 & Kahulunge & Tanzania \\
\hline
\end{tabular}

Table 2. Characteristics of the eight test environments used in the evaluation of 81 finger millet accessions in 2011 and 2012

\begin{tabular}{|c|c|c|c|c|c|c|c|c|}
\hline \multirow[t]{2}{*}{ Location } & \multirow[t]{2}{*}{ Environment codes } & \multirow[t]{2}{*}{ Altitude (m) } & \multirow[t]{2}{*}{ Latitude } & \multirow[t]{2}{*}{ Longitude } & \multicolumn{3}{|c|}{ Temperatures $\left({ }^{\circ} \mathrm{C}\right)$} & \multirow[t]{2}{*}{ Mean annual rainfall (mm) } \\
\hline & & & & & Min & Max & Mean & \\
\hline Alupe (Kenya) & Alu11SR, Alu12LR & 1189 & $0^{\circ} 28^{\prime} \mathrm{N}$ & $34^{\circ} 7^{\prime} \mathrm{E}$ & 17.7 & 30.3 & 24.0 & 1100 \\
\hline Lanet (Kenya) & Lan12LR & 1920 & $0^{\circ} 30^{\prime} \mathrm{S}$ & $36^{\circ} 0^{\prime} \mathrm{E}$ & 10.0 & 20.0 & 15.0 & 850 \\
\hline Kiboko (Kenya) & Kib11SR, Kib12LR & 9 & $2^{\circ} 20^{\prime} \mathrm{S}$ & $37^{\circ} 45^{\prime} \mathrm{E}$ & 16.6 & 29.4 & 23.0 & 604 \\
\hline Serere (Uganda) & Ser12LR & 1000 & $1^{\circ} 31^{\prime} \mathrm{N}$ & $33^{\circ} 27^{\prime} \mathrm{E}$ & 18.0 & 30 & 24.0 & 1378 \\
\hline Miwaleni Tanzania) & Miw12LR & 500 & $3^{\circ} 25^{\prime} \mathrm{S}$ & $37^{\circ} 27^{\prime} \mathrm{E}$ & 16.5 & 27.0 & 21.7 & 650 \\
\hline Uyole (Tanzania) & Uyol12 & 1800 & $8^{\circ} 55^{\prime} \mathrm{S}$ & $33^{\circ} 34^{\prime} \mathrm{E}$ & 7.9 & 19.3 & 13.5 & 870 \\
\hline
\end{tabular}

Al11SR - Alupe 2011 short rains, Alu12LR - Alupe 2012 long rains, Kib11SR - Kiboko2011 short rains, Kib12LR - Kiboko 2012 long rains, Lan12LRLanet 2012 long rains, Miw12LR - Miwaleni 2012 long rains, Uyol12 - Uyole 2012, Ser12LR - Serere 2012 long rains

days to $50 \%$ flowering (when half of the plants in the plot had started flowering) plant height (from the base of the stem to the tip of the panicle at hard dough stage in $\mathrm{cm}$ ), grain yield $\mathrm{t} \mathrm{ha}{ }^{-1}$ ). The trials were conducted under rain grown conditions at all environments except at Kiboko and Miwaleni where supplementary irrigation was applied during very dry periods up to flowering.

\section{Data Analysis}

\section{GGE Biplot Analysis}

For GGE biplot analysis, Yan (2002) model based on the singular value decomposition (SVD) of the first two principal components was used in Genstat 15.0 (http:// www.genstat.co.uk). The GGE biplots were interpreted 
according to Yan et al. (2001) and Yan (2002) and used to discriminate the environments.

\section{Results}

\section{Discriminatory Ability and Representativeness of Test Environments}

The GGE biplot explained $46.1 \%$ of the total G×E interaction for grain yield (Fig. 1). High correlations were detected between Miw12LR, Kib11SR, Kib12LR, Alu11SR and Alu12LR and between Lan12LR and Uyol12. The environments were placed in three groups based on inter-environment distances (Fig. 1). Group one comprised the Alu11SR, Alu12LR, Kib11SR, Kib12LR and Miw12LR, group two comprised the two cool highlands environments Lan12LR and Uyol12, and Ser12LR stood alone. Although Ser12LR grouped alone, it was significantly $(\mathrm{P} \leq 0.01)$ positively correlated to Alu12LR. The most discriminative environment for grain yield was Lan12LR. The best performing genotypes for grain yield per mega-environment (and furthest from the biplot origin) were genotypes 74, 32, 71 and 28 for Ser12LR (74 best adapted), genotypes 1, 21, 20, 23 for Alu11SR, Alu12LR, Kib11SR, Kib12LR and Miw12LR
( 1 best adapted), and genotypes 37, 35, 71 and 75 for Lan12LR and Uyol12 (37 best adapted) (Fig. 1).

\section{Genotype Ranking Based on Mean Grain Yield and Stability}

Genotypes 74, 32, 71 and 28 had the highest mean yield regardless of stability and 5, 12, 25, 27, 30, 33, 48, 56 and 76, were most stable regardless of yield. Genotypes 3, 5, 17, 25, 28, 36, 42, 45, 56 and 71 were highly stable with grain yield above the grand mean across environments (Fig. 2 and Table 3). Genotypes 15 and 70 were unstable with the lowest grain yield whereas genotypes 27, 30, 33, 48, 54, 65 and 78 were stable but with low yield.

\section{Discussion}

\section{Discriminatory Power and Representativeness of Test Environments}

The most discriminating environment will give the most information about the genotypes and it is characterized by long vectors from the biplot origin (Yan and Tinker, 2006). For grain yield, Lan12LR followed by Miw12LR and Ser12LR were the most informative

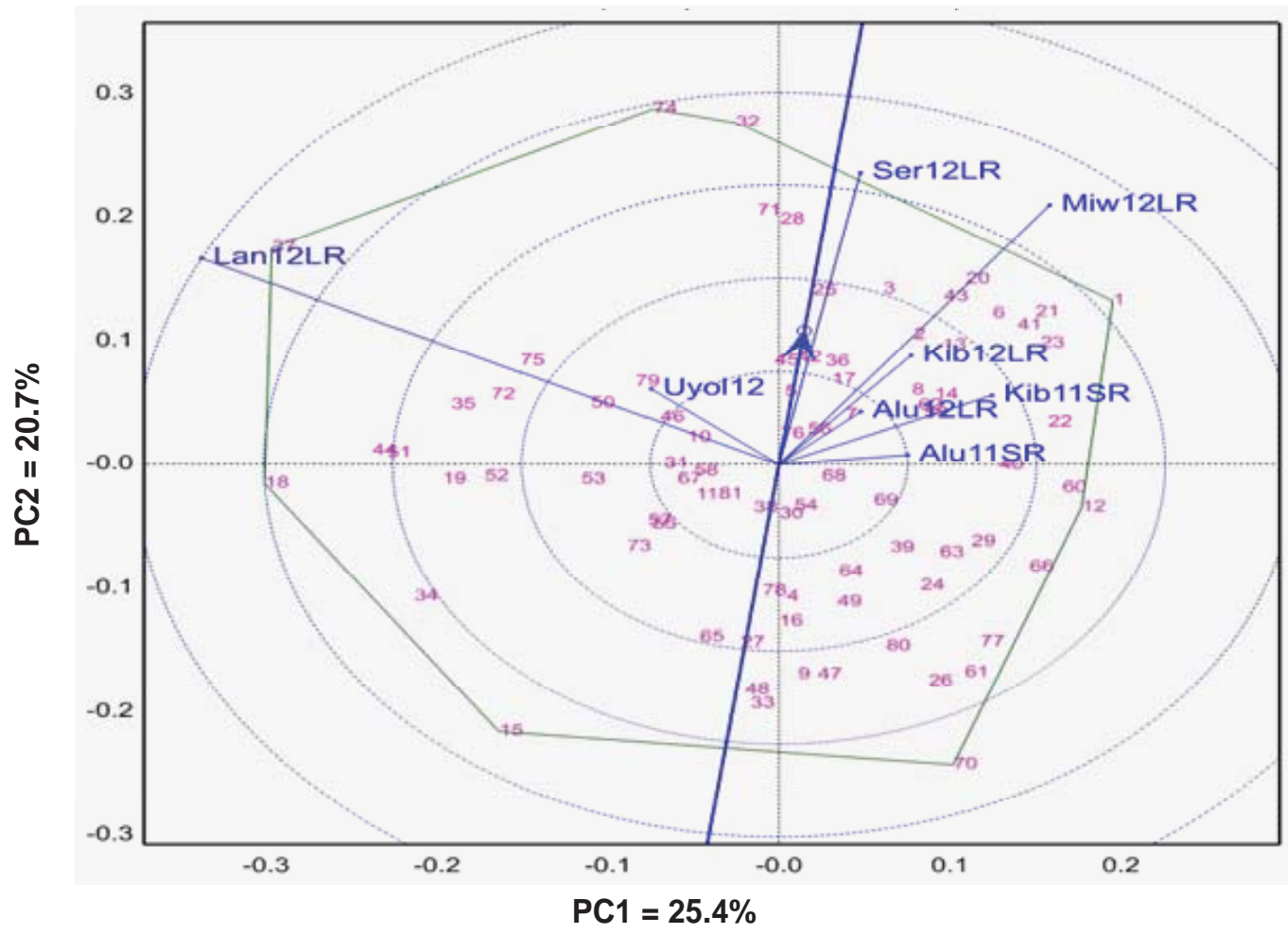

Fig. 1. Discriminatory ability and representativeness of the eight test environments for grain yield (t ha' $\left.{ }^{-1}\right)$ 


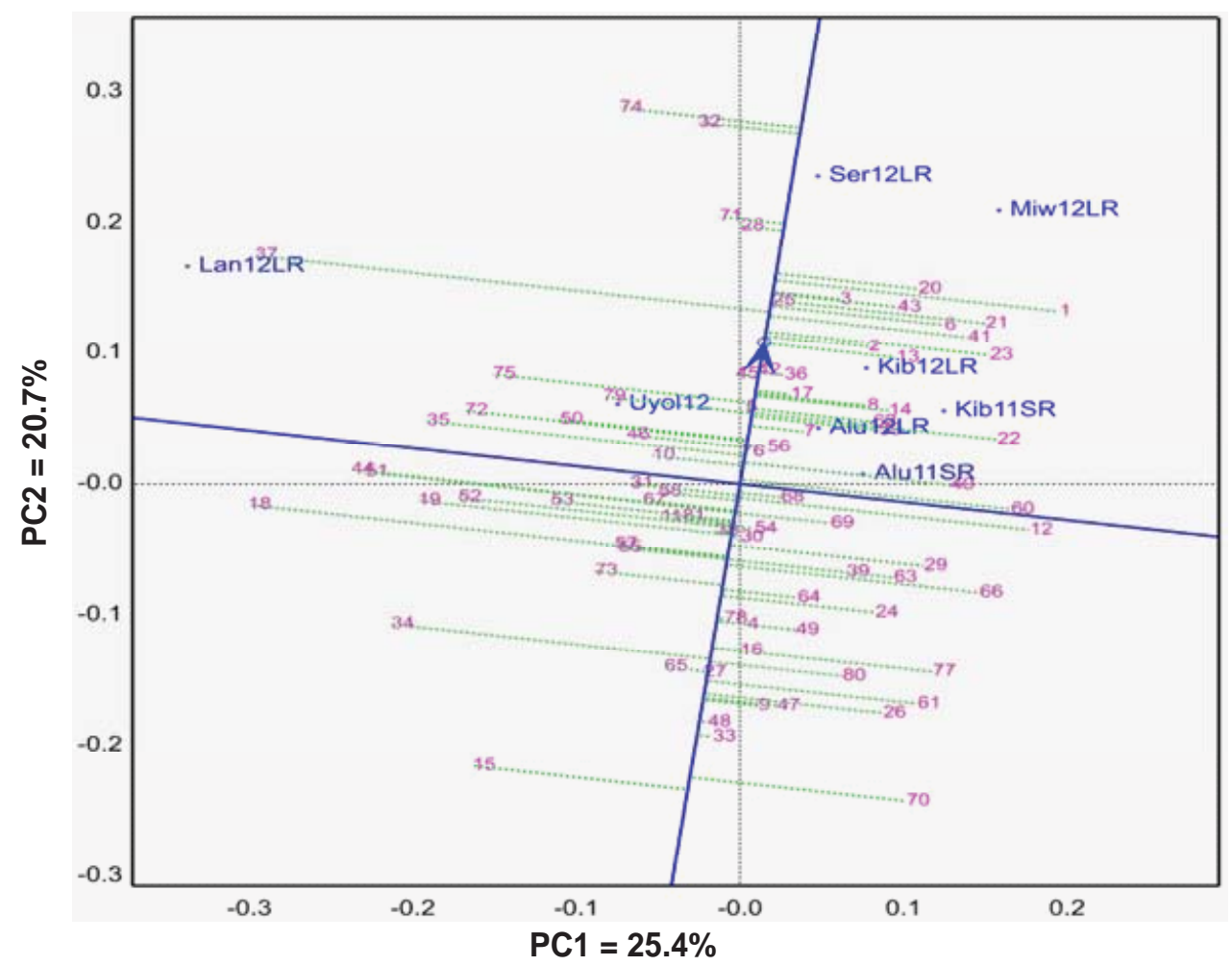

Fig. 2. Genotype ranking based on mean grain yield and stability across the environments

Table 3. Grain yield, plant height, days to flowering of stable genotypes

\begin{tabular}{lccc}
\hline Genotype & Grain yield $\left(\mathrm{t} \mathrm{ha}^{-1}\right)^{\mathrm{a}}$ & ${\text { Plant height }(\mathrm{cm})^{\mathrm{a}}}^{\mathrm{a}}$ & Days to flowering $^{\mathrm{a}}$ \\
\hline G3 & 3.13 & 71.5 & 81 \\
G5 & 2.75 & 75.0 & 76 \\
G17 & 2.79 & 83.0 & 82 \\
G25 & 2.52 & 78.0 & 82 \\
G28 & 2.90 & 81.7 & 87 \\
G30 & 2.45 & 74.4 & 75 \\
G36 & 2.51 & 78.5 & 81 \\
G56 & 2.34 & 79.5 & 83 \\
G71 & 2.66 & 81.0 & 97 \\
\hline Grand mean $(\mathbf{N}=\mathbf{8 1})$ & 2.14 & 86.7 & 78 \\
\hline
\end{tabular}

${ }^{a}$ Across eight environments, Al11SR - Alupe 2011 short rains, Alu12LR - Alupe 2012 long rains, Kib11SR - Kiboko2011 short rains, Kib12LR - Kiboko 2012 long rains, Lan12LR - Lanet 2012 long rains, Miw12LR - Miwaleni 2012 long rains, Uyol12 - Uyole 2012, Ser12LR - Serere 2012 long rains

environments whereas Alu12LR and Alu11SR were the least informative. Based on polygon biplot, there were three mega-environment groups with the cool high elevation environments Lan12LR and Uyol12 in one mega-environment; Alu11SR, Alu12LR (sub-humid, mid-altitude), Kib11SR, Kib12LR and Miw12LR (dry lowlands) in another group; and Ser12LR (sub humid mid-altitude) on its own. Although, Ser12LR formed its own mega-environment, its significant positive correlation with Alu12LR was more realistic as these two environments fall within the same sub-humid zone with similar mean temperatures and rainfall. Ser12LR was the most representative test environment in terms of average interaction effects with the genotypes in terms of PC1 and PC2 and relative to environments and genotypes evaluated whereas Lan12LR and Alu12SR were the least representative for grain yield. Ser12LR was also highly discriminating for grain yield and hence useful for carrying out selection for both general and specific adaptation to sub-humid environments. Hopkins 
(1938) alluded to the fact that phenological development of plants can differ by four days for every degree of latitude. Therefore, Lan12LR would be ideal for low temperature genotype discrimination, it should be utilized separately from Uyol12 when selecting for specific and general adaptation considering the differences in latitude $\left(5^{\circ}\right)$ between the two environments.

\section{Genotype Ranking Based on Mean Yield and Stability Indices}

The vertex (winning) genotypes in each environment based on polygon rays of GGE biplots were: 1 in the mega-environment grouping of Alu11SR Alu12LR, Kib11SR, Kib12LR and Miw12LR environments, genotype 74 in Ser12LR and genotype 37 in Lan12LR and Uyol12. The highest yielding genotypes in each of the three mega-environment were 74, 32, 71 and 28 in Ser12LR; 1, 21, 20, and 23 in Alu11SR, Alu12LR, Kib11SR, Kib12LR and Miw12LR; and 37, 35, 71 and 75 in Lan12LR and Uyol12. Selection of suitable genotypes is based on both yield per se and stability. Yan and Kang (2003) described an ideal genotype as one having the highest mean and stability represented by the longest vector from origin and short AEC ordinate and zero GEI in a GGE biplot. High stability and above average mean grain yields were recorded in genotypes $3,5,17,25,28,36$, and 71 . These genotypes were early to medium in flowering, had average height and moderate resistance to blast. However genotypes 25, 30 , and 71 may be best utilized in environments with low incidence of blast as they were susceptible to all three blast types.

\section{Conclusions}

The high elevation low temperature finger millet production environments were distinctly separated from the warmer mid-altitudes and lowlands environments. Lan12LR was identified as an ideal environment to discriminate low temperature adapted genotypes, Ser12LR for sub-humid environments and Miw12LR for the dry lowlands for grain yield. Adaptation testing for the low temperature environments Lan12LR and Uyol12 may be handled separately considering large differences in latitude between them. Genotypes 3, 5, $17,25,28,36$ and 71 were identified to be stable across the eight environments based on grain yield. Genotypes 1, 18, 19, 37, 54, 61, 74, 75 and 77 were identified for specific adaptation.

\section{Acknowledgement}

We are grateful to the Bill and Melinda Gates Foundation for funding this work through the Harnessing Opportunities for Productivity Enhancement of Sorghums and Millets (HOPE) project.

\section{References}

Bandyopadhyay BB (2009) Yield variation and associated changes in relationship of component characters of a cold sensitive finger millet genotype in subsequent generation. $J$. Agric. Res. 43: 32-36.

Bezaweletaw K, Sripichitt P, Wongyai W and Hongtrakul V (2006) Genetic variation, heritability and path-analysis in Ethiopian finger millet (Eleusine coracana (L.) Gaertn) landraces. Kasetsart J. (National Science) 40: 322-334.

Das S, Misra RC, Das SR, Patnaik MC and Sinha SK (2011) Integrated analysis for genotypic adaptation in rice. Afr. Crop Sci. J 19: 15-28.

GenStat 15th Edition for Windows. (http://www.vsni.co.uk).

Hopkins AD (1938) Bioclimatics - a science of life and climate relations. Miscellaneous Publication 280. United States Department of Agriculture, US Forest Service, Washington, DC, USA, 188 p.

Joshi BK, Tiwari RK, Amgain RB, Shrestha P, Gyawali S, Mudwariand A and Baniya BK (2005) Stability and adaptation of finger millet (Eleusine coracana (L) Gaertn.) landraces. In: Sthapit, BR, Upadhyaya, MP, Shrestha, PK, Jarvis, DI (eds.). On Farm Conservation of Agricultural Biodiversity in Nepal. Vol. 1. Assessing the Amount and Distribution of Genetic Diversity On-farm.

Misra RC, Das S and Patnaik MC (2010) AMMI analysis of stability and adaptability of late duration Finger Millet (Eleusine coracana) genotypes. World J. Agri. Sci. 6: 664-669.

Oduori COA (2008) Breeding investigations of finger millet characteristics including blast disease and striga resistance in western Kenya. PhD Thesis, University of Kwazulu, Natal, South Africa.

Opole RA (2012) Effect of environmental stress and management on grain and biomass yield of finger millet [Eleusine coracana (L.) Gaertn.]. PhD thesis, Department of Agronomy College of Agriculture, Kansas State University Manhattan, Kansas, USA.

Yan W (2002) Singular-value partitioning in biplot analysis of multi-environment trial data. Agronomy J. 94: 990-996.

Yan W, Sheng Q, Hu YG and Hunt LA (2001) GGE biplot-an ideal method for graphical analysis of genotype by environment interaction. Acta Agronomica Sinica 27: 21-28.

Yan W and Kang MS (2003) GGE Biplot Analysis: A Graphical Tool for Breeders, Geneticists, and Agronomists. CRC Press, Boca Raton, FL.

Yan W and Tinker NA(2006) Biplot analysis of multi-environment trial data: Principles and applications. Can. J. Plant Sci. 86: $623-645$. 